\title{
Quantitative In Vivo Studies on the Active Na-K Transports in "Tonic". Muscle of the Hypokalemic Rat
}

\author{
Norio AKaike, Toshikazu Kiyohara,* and Yasuo Oyama** \\ Department of Physiology, Faculty of Medicine, Kyushu \\ University, Fukuoka, Fukuoka, 812 Japan \\ *Department of Physiology, Saga Medical School, Saga, \\ Saga, 840-01 Japan \\ **Department of Pharmacology, Kumamoto University Medical School, \\ Kumamoto, Kumamoto, 860 Japan
}

\begin{abstract}
Central nervous system (CNS)-induced suppression on the muscle Na-pump activity was studied in soleus (SOL) muscles of hypokalemic rats. Peripheral nerve section, cervical soleus and brainstem transection, decerebration, and cortical spreading depression with $20 \% \mathrm{KCl}$ activated the Na-pump in SOL muscles during hypokalemia. Blockage of the nerve conduction by tetrodotoxin (TTX) also activated the Na-pump in SOL muscles. The activation of Na-pump after the denervation was completely abolished by the pre-treatment of ouabain. However, the muscle cation contents were not affected by the injection of curare and atropine. The activation of Na-pump in the muscles after denervation in the curarized hypokalemic rats was completely removed by electrical stimulus of the distal nerve stump of cut sciatic nerve. $\alpha$-Adrenoreceptor antagonists (phenoxybenzamine, phentolamine and dibenamine, and prazosin) stimulated the $\mathrm{Na}^{+}$and $\mathrm{K}^{+}$transports in the SOL muscles during hypokalemia while $\beta$-adrenoreceptor antagonist (propranolol) had no effect. The denervation effect on SOL muscle cation contents was not affected with or without the presence of propranolol. It is concluded that CNS acts to inhibit the Na-pump mechanism in SOL muscles of hypokalemic rats and the inhibition is achieved by the apparent release of catecholamines onto muscle following neural activity. Thus, the CNS-induced suppression on the muscle Na-pump is prevented by denervation and by treatment with drugs that block either nerve conduction or $\alpha$-adrenoreceptor.
\end{abstract}

Key Words: CNS, denervation, soleus, Na-pump, $\alpha_{1}$-receptor.

Subjecting rats to potassium-deficient diets results in a fall of $\mathrm{K}^{+}$concentration in blood plasma and skeletal and smooth muscles but no effect has been noted in

Received for publication December 17, 1982

赤池紀扶，清原寿一，小山保夫 
liver, cerebrospinal fluid, and brain tissues such as cerebrum, cerebellum, medulla oblongata, and spinal cord (BRADBURY and KLEEMAN, 1967; JOHANSON et al., 1974; NATtie, 1977; AKaike, 1979, 1981; NøRgAARD et al., 1981; AKAIKE et al., 1983). In hypokalemic rats for 5 to 7 weeks, however, the plasma $\mathrm{K}^{+}$levels do not fall much below $1.6 \mathrm{mM}$, which is a sufficient amount to maintain the $\mathrm{Na}^{+}-\mathrm{K}^{+}$active transports in slow "tonic" muscle, soleus (SOL) (AKAIKE, 1974, 1975, 1976), since when these SOL muscles from hypokalemic rats were excised and placed in a Krebs solution with $\mathrm{K}^{+}$more than $1.5 \mathrm{~mm}$ at $37^{\circ} \mathrm{C}$, the intracellular $\mathrm{Na}^{+}$concentration $\left([\mathrm{Na}]_{\mathrm{i}}\right)$ was reduced while the intracellular $\mathrm{K}^{+}$concentration $\left([\mathrm{K}]_{\mathrm{i}}\right)$ was increased with time. Thus, the high $[\mathrm{Na}]_{\mathrm{i}}$ and low $[\mathrm{K}]_{\mathrm{i}}$ in SOL muscles in vivo of hypokalemic rats are not due to the direct result of the pump inhibition by plasma hypokalemia but to an additional mechanism which suppresses the active $\mathrm{Na}^{+}$$\mathrm{K}^{+}$transports in vivo conditions.

It has been shown quantitatively in the present study that the central nervous system (CNS) of hypokalemic rats directly imposes an inhibition on the active $\mathrm{Na}^{+}-\mathrm{K}^{+}$transports in the SOL muscles and that the CNS-induced inhibition on the muscle is mediated via $\alpha_{1}$-adrenoreceptors on the muscle membrane. A preliminary account of some of these results has been presented as short communications (AKAIKE, 1979, 1981).

\section{METHODS}

The experiments were performed on SOL as "tonic" muscle of male Wistar rats weighing between 230 and $300 \mathrm{~g}$. The rats were housed in a temperature and humidity controlled room. The rats were fed potassium-deficient diet and deionized water ad libitum for 5 to 9 weeks. All rats were in good health at the time of the experiments.

Surgical procedure. Rats were anesthetized with ether. Depending on the purpose of the experiments, the CNS action on the $\mathrm{Na}^{+}$and $\mathrm{K}^{+}$contents in SOL muscles was examined by sectioning the tibial nerve branch and sciatic nerve, by transectioning cervical spinal cord and brain stem, by decerebration, and by cortical spreading depression. Figure 1 schemalizes the arrangement of nerve section or transection at different points and decerebration. The procedures of each surgical operation are described in detail in text.

Electrolyte measurements. The SOL muscles were excised and prepared for $\mathrm{Na}^{+}$and $\mathrm{K}^{+}$analyses at the end of experiment. Chemical analyses of $\mathrm{Na}^{+}$and $\mathrm{K}^{+}$ contents in the muscles and plasma samples were carried out with a flame spectrophotometer. The intracellular $\mathrm{Na}^{+}$and $\mathrm{K}^{+}$concentrations of muscles $\left(C_{\mathrm{f.w} .}\right)$ were calculated from the total cation contents of tissues $\left(C_{\mathrm{m}}\right)$, the plasma cation contents $\left(C_{\mathrm{o}}\right)$, the extracellular space $(v)$, and the dry-to-wet-weight ratio (d.w./ w.w.) by

$$
C_{\mathrm{f} . \mathrm{w} .}=\frac{C_{\mathrm{m}}-v C_{\mathrm{o}}}{1-(\mathrm{d} . \mathrm{w} \cdot / \mathrm{w} \cdot \mathrm{w} \cdot+v)} \quad(\mathrm{mmol} / \text { liter fiber water })
$$



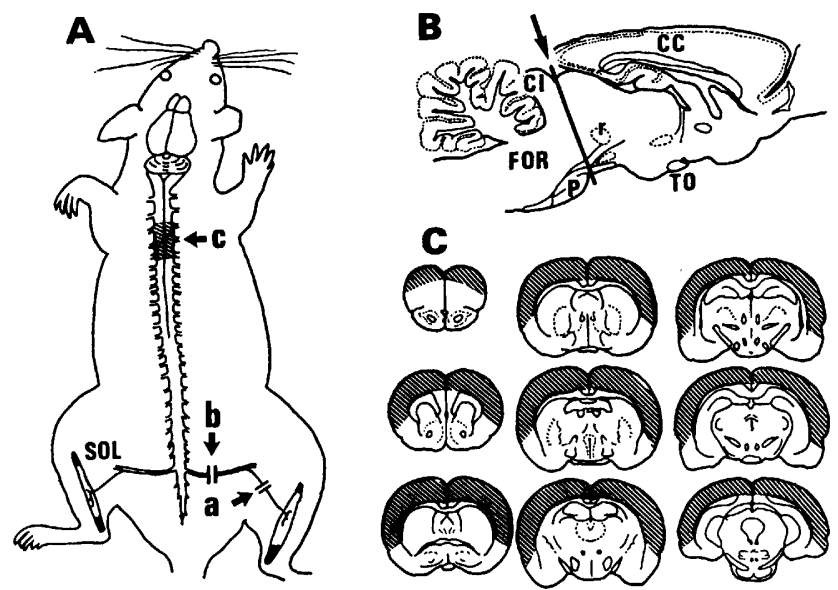

Fig. 1. A, schematic diagram of SOL muscles of rat and its nerve supply. $a, b$, and $c$ indicate the approximate levels of nerve section at the tibial nerve branch, sciatic nerve, and $\mathrm{C}_{3}$ to $\mathrm{C}_{5}$ regions of spinal cord, respectively. $\mathrm{B}$, diagram of the rat brain showing the transection at the intercollicular level. CC, cerebral cortex; CI, inferior colliculus; FOR, reticular formation; $\mathrm{P}$, pontine nuclei; TO, optic tract; and $\mathrm{r}$, red nucleus. C, schematic drawing of decerebration. Coronal sections showing, in hatched, the tissue loss common to all neodecorticates. Figures redrawn from KöNIG and KLIPPEL (1963).

where $C_{\mathrm{m}}$ is expressed as $\mathrm{mmol} / \mathrm{kg}$ wet weight, $C_{\mathrm{o}}$ as $\mathrm{mmol} / \mathrm{liter}$, and $v$ as liters/ $\mathrm{kg}$ wet weight (DESMEDT, 1953). The extracellular space was calculated from the formula relating the space $(y)$ to the muscle weight $(x), y=(659.8 / x)+2.67$, and this was applied to both innervated and denervated SOL muscles in the hypokalemic rats. The dry-to-wet-weight ratio was assumed to be 0.226 for the innervated and denervated SOL muscles, since the dry-to-wet-weight ratio changes little in the initial days following the denervation.

Drugs. Atropine (Tanabe), curare (Yoshitomi), ouabain (Takeda), tetrodotoxin (TTX; Sankyo), ether (Wako), phenoxybenzamine (Tokyo Kasei), phentolamine (Ciba), dibenamine (Tokyo Kasei), prazosin (Taito Phizer), and propranolol (ICI) were used.

Statistical method. The data have been analyzed statistically using Student's $t$-test to evaluate differences within several experimental series. The numerical values are given as mean values \pm 1 S.D. In the figures, \pm 1 S.D. is indicated by bars.

\section{RESULTS}

\section{Peripheral nerve section}

The distal denervation of SOL muscles of potassium-deprived rats for 5 to 9 weeks was accomplished unilaterally by exposing and sectioning the tibial nerve branch just proximal to their point of insertion into the muscles. The contra- 


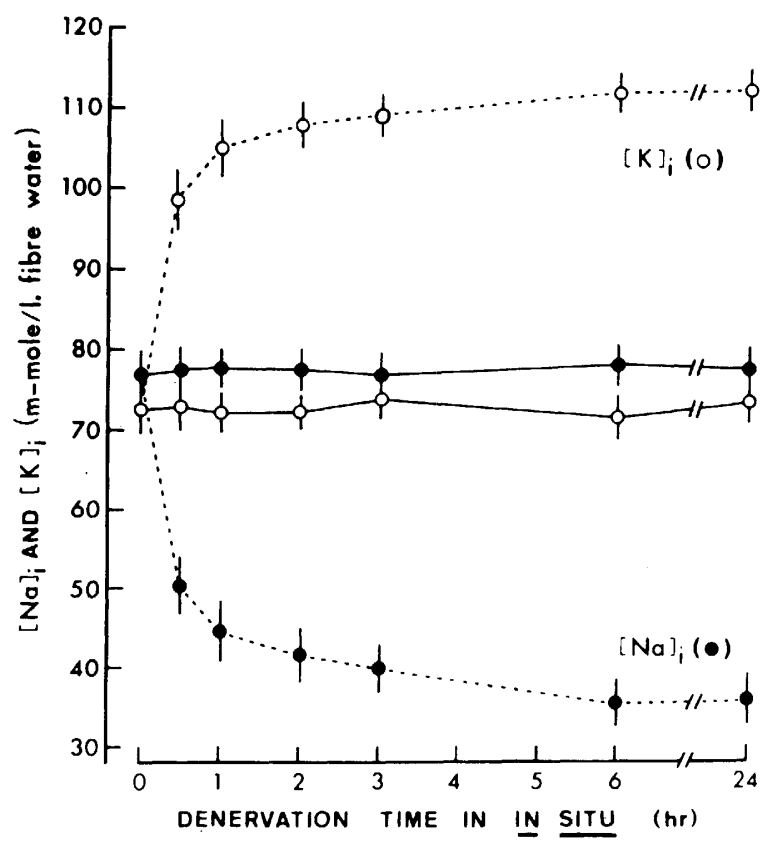

Fig. 2. Effects of sectioning the tibial nerve branch on the active $\mathrm{Na}^{+}$and $\mathrm{K}^{+}$transports in SOL muscles of hypokalemic rats for about 5 to 9 weeks. Open circles, the intracellular $\mathrm{K}^{+}$concentration. Filled circles, the intracellular $\mathrm{Na}^{+}$concentration. Solid lines indicate the innervated muscles while dotted lines represent the denervated muscles. Each point represents the average value of 9 to 11 preparations. Ordinate, $[\mathrm{Na}]_{i}$ and $[\mathrm{K}]_{1}$ (mmol/liter fiber water). Abscissa, time in hour after the nerve section. Note a rapid and dramatic $\mathrm{Na}^{+}$extrusion and $\mathrm{K}^{+}$uptake in the denervated muscles.

lateral nerves were sham-operated, and the contralateral companion muscles served as each control. The muscles from each pair were dissected out at various intervals following the surgical procedure and prepared for $\mathrm{Na}^{+}$and $\mathrm{K}^{+}$analyses. The $[\mathrm{Na}]_{i}$ and $[\mathrm{K}]_{\mathrm{i}}$ between the innervated and denervated muscles were compared with each other. Figure 2 shows an unexpected dramatic reversal of the effects of hypokalemia on $[\mathrm{Na}]_{1}$ and $[\mathrm{K}]_{\mathrm{i}}$ levels in SOL muscle elicited by the sectioning of the tibial nerve branch. The denervated SOL muscles were promptly capable of restoring their $[\mathrm{Na}]_{\mathrm{i}}$ and $[\mathrm{K}]_{\mathrm{i}}$ levels towards the values of the "fresh" ones in normal rats (Table 1). The internal cation contents reached the plateau recovery values within $6 \mathrm{hr}$ after denervation, thereafter the recovered $[\mathrm{Na}]_{\mathrm{i}}$ and $[\mathrm{K}]_{\mathrm{i}}$ remained unchanged for several days. The half recovery time of these cations was about $20 \mathrm{~min}$, even at which time there was a highly significant difference in $[\mathrm{Na}]_{\mathrm{i}}$ or $[\mathrm{K}]_{\mathrm{i}}$ between the innervated and denervated SOL muscles $(P<0.001)$. In addition, the denervation for $3 \mathrm{hr}$ had no effects on the internal $\mathrm{Na}^{+}$and $\mathrm{K}^{+}$contents in SOL muscles of normal rats (Table 1).

Sectioning a motor nerve to mammalian skeletal muscle produces not only 
Table 1. Effects of denervation at different levels on the intracellular $\mathrm{Na}^{+}$and $\mathrm{K}^{+}$ concentrations in SOL muscles of hypokalemic rate for 5 to 9 weeks.

\begin{tabular}{|c|c|c|c|}
\hline Preparation & $\begin{array}{l}\text { Muscle } \\
\text { weight } \\
\text { (mg) }\end{array}$ & $\begin{array}{l}{[\mathrm{Na}]_{\mathrm{i}}} \\
(\mathrm{mmol} / \mathrm{liter}\end{array}$ & $\begin{array}{c}{[\mathrm{K}]_{\mathrm{I}}} \\
\text { iber water) }\end{array}$ \\
\hline \multicolumn{4}{|l|}{ Normal rats } \\
\hline Control muscles connected to CNS & $80 \pm 3.3(9)$ & $24.9 \pm 2.0$ & $132.4 \pm 2.2$ \\
\hline $\begin{array}{l}\text { Companion muscles denervated at } \\
\text { tibial nerve branch }\end{array}$ & $79 \pm 3.4(9)$ & $25.2 \pm 1.9$ & $132.6 \pm 2.1$ \\
\hline Net change & & $(+0.3)$ & $(+0.2)$ \\
\hline \multicolumn{4}{|l|}{ Hypokalemic rats } \\
\hline Control muscles connected to CNS & $82 \pm 3.7(11)$ & $71.8 \pm 4.3$ & $79.6 \pm 2.6$ \\
\hline $\begin{array}{l}\text { Companion muscles denervated at } \\
\text { tibial nerve branch }\end{array}$ & $81 \pm 3.5(11)$ & $36.8 \pm 2.2$ & $113.1 \pm 2.8$ \\
\hline Net change & & $(-35.0)^{*}$ & $(+33.5)^{*}$ \\
\hline Control muscles connected to CNS & $76 \pm 1.6(15)$ & $75.1 \pm 1.5$ & $81.3 \pm 2.3$ \\
\hline $\begin{array}{l}\text { Companion muscles denervated at } \\
\text { sciatic nerve }\end{array}$ & $75 \pm 1.4(15)$ & $38.6 \pm 1.4$ & $116.0 \pm 3.5$ \\
\hline Net change & & $(-36.5)^{*}$ & $(+34.7)^{*}$ \\
\hline Control muscles connected to CNS & $68 \pm 2.8(12)$ & $73.7 \pm 2.4$ & $77.1 \pm 1.9$ \\
\hline $\begin{array}{l}\text { Companion muscles } 3 \mathrm{hr} \text { after } \\
\text { cervical transection }\end{array}$ & $66 \pm 2.1(12)$ & $39.2 \pm 0.9$ & $108.9 \pm 1.3$ \\
\hline Net change & & $(-34.5)^{*}$ & $(+31.8)^{*}$ \\
\hline Control muscles connected to CNS & $86 \pm 4.2(7)$ & $73.5 \pm 3.7$ & $71.7 \pm 3.6$ \\
\hline $\begin{array}{l}\text { Companion muscles } 3 \mathrm{hr} \text { after } \\
\text { brainstem transection }\end{array}$ & $80 \pm 3.5(7)$ & $42.7 \pm 1.2$ & $106.1 \pm 3.6$ \\
\hline Net change & & $(-30.8)^{*}$ & $(+34.4)^{*}$ \\
\hline Control muscles connected to CNS & $70 \pm 4.0(8)$ & $71.7 \pm 4.1$ & $71.9 \pm 4.6$ \\
\hline $\begin{array}{l}\text { Companion muscles } 3 \mathrm{hr} \text { after } \\
\text { decerebration by suction }\end{array}$ & $70 \pm 5.4(8)$ & $40.7 \pm 2.0$ & $108.0 \pm 3.2$ \\
\hline Net change & & $(-31.0)^{*}$ & $(+36.1)^{*}$ \\
\hline Control muscles connected to CNS & $83 \pm 3.4(6)$ & $72.2 \pm 3.8$ & $73.1 \pm 2.1$ \\
\hline $\begin{array}{l}\text { Companion muscles } 3 \mathrm{hr} \text { after } \\
\text { local application of } 20 \% \mathrm{KCl}\end{array}$ & $82 \pm 5.2(6)$ & $46.1 \pm 2.2$ & $96.5 \pm 3.1$ \\
\hline Net change & & $(-26.1)^{*}$ & $(+23.4)^{*}$ \\
\hline
\end{tabular}

Companion muscles remained in vivo for $3 \mathrm{hr}$ after the nerve section. Symbols $\left(^{*}\right)$ indicate significant difference at $P<0.001$. Twenty $\% \mathrm{KCl}$ was repeatedly applied at every $20 \mathrm{~min}$ (see text). The number of preparations is shown in parentheses. Values listed are the means \pm 1 S.D.

immediate loss of impulses from CNS to periphery but also TTX-resistant action potential, ACh hypersensitivity, new formation of mRNA, and the ionic composition change 2 days after the nerve section (KIYOHARA, 1968; REDFERN and TheslefF, 1971; THESLEFF and WARD, 1975). Nerve plays an important role in maintaining the integrity and function of muscle fiber, and onset of ACh supersensitivity in denervated muscle depends upon the length of peripheral residual nerve stump (GUTH, 1968). Therefore, the effect of difference in the length of residual nerve stump remaining after the denervation was made unilaterally by exposing and sectioning the sciatic nerve proximal to spinal cord of hypokalemic 


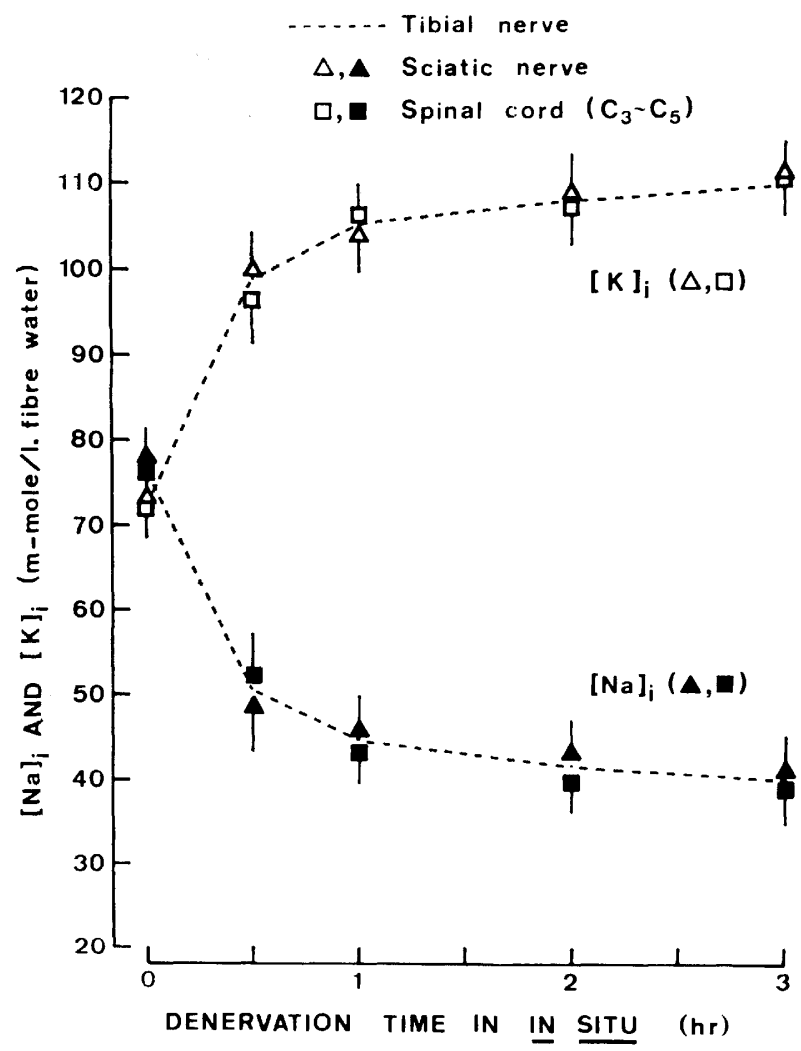

Fig. 3. The active $\mathrm{Na}^{+}-\mathrm{K}^{+}$transports in the denervated SOL muscles elicited by sectioning sciatic nerve or spinal cord $\left(\mathrm{C}_{3}\right.$ to $\mathrm{C}_{5}$ levels). Sciatic nerve section, $[K]_{i}(\triangle)$ and $[\mathrm{Na}]_{i}$ (A). Cervical transection, $[K]_{i}(\square)$ and $[N a]_{i}(\square)$. Dotted lines were quoted from Fig. 2, in which denervation was made by sectioning tibial nerve branch. Points are means of 12 to 15 muscles. Ordinate, $\left[\mathrm{Na}_{\mathrm{i}}\right.$ and $[\mathrm{K}]_{\mathrm{i}}$ in $\mathrm{mmol} / \mathrm{liter}$ fiber water. $\mathrm{Ab}$ scissa, time in hour after sectioning sciatic nerve or spinal cord.

rats. The contralateral sciatic nerve was also sham-operated. The treatment gave quite the same result on $\mathrm{Na}^{+}$and $\mathrm{K}^{+}$contents in SOL muscles as well as that found in the muscles after sectioning the tibial nerve branch (Fig. 3 and Table 1).

\section{CNS transection and decerebration}

To further characterize the neural control on the $\mathrm{Na}^{+}$and $\mathrm{K}^{+}$contents in SOL muscles of hypokalemic rats for 6 to 8 weeks, cervical transection was done at the level of $\mathrm{C}_{3}$ to $\mathrm{C}_{5}$, during which time the animals were maintained on an artificial respirator. In this experiment, one muscle from each pair of SOL muscles was dissected out as a control before the cervical section and then prepared for $\mathrm{Na}^{+}$ and $\mathrm{K}^{+}$analyses. Afterwards, the cervical spinal cord was exposed by laminectomy with a pair of corneal scissors. The companion muscle remained in vivo 
for various periods following the cervical transection. Then, the amount of $[\mathrm{Na}]_{i}$ and $[\mathrm{K}]_{\mathrm{i}}$ was estimated and compared with the concentrations in the control muscles. Sectioning at the cervical level also resulted in a recovery of $[\mathrm{Na}]_{\mathrm{i}}$ and increase of $[\mathrm{K}]_{\mathrm{i}}$ in the SOL muscles (Table 1). As is shown in Fig. 3, it is an astonishing experimental fact that no differences were found among time courses in dramatic shifts of $[\mathrm{Na}]_{i}$ and $[\mathrm{K}]_{i}$ in SOL muscles after tibial nerve section, sciatic nerve section and cervical transection.

For midbrain transection at an intercollicular level or for decerebration in which neocortical ablations were made by suction, one muscle from each pair of SOL muscles of hypokalemic rats which were fixed in a stereotaxic instrument, was dissected out as a control before transection or decerebration and then prepared for the electrolyte analysis. The companion muscle remained in vivo for $3 \mathrm{hr}$ after the surgical operation. Thereafter, $[\mathrm{Na}]_{\mathrm{i}}$ and $[\mathrm{K}]_{\mathrm{i}}$ values in this muscle were estimated and compared with those in the control muscle. At the conclusion of both experiments, animals were given lethal injection of pentobarbital and perfused intra-aortically with normal saline followed by $10 \%$ formalin. The brains were removed and the site and extent of transections and cortical ablations were checked histologically. Consequently, both brainstem transection and decerebration could also recover the $\mathrm{Na}^{+}$and $\mathrm{K}^{+}$contents in SOL muscles (Table 1).

Telencephalic influences on the $\mathrm{Na}^{+}$and $\mathrm{K}^{+}$contents in SOL muscle have also been studied with the cortical spreading depression (CSD) technique as functional decortications (LEÃO, 1947; BuREŠ and BurEšovÁ, 1972; Bureš et al., 1974). One muscle from each pair of SOL muscles of hypokalemic rats was dissected out as control before the CSD experiments. Then, prolonged CSDs were bilaterally elicited by applying a filter paper soaked with $20 \% \mathrm{KCl}$ solution on the parietofrontal cortical surface through a skull opening $3 \mathrm{~mm}$ in diameter. The parietofrontal area was chosen as a CSD focus since CSD propagating ( 3 to $5 \mathrm{~mm} / \mathrm{min}$ ) both frontally and occipitally from this focus ensures a maximum effect of functional decortication. The dura of the exposed cortex remained intact. The filter paper was replaced by a new one each 20 min over a period of $3 \mathrm{hr}$ because a single application of the filter paper soaked with the solution elicits CSDs for at least 40 to $50 \mathrm{~min}$ (Shibata, personal communication). As shown in Table 1, there was a marked recovery of the effects of hypokalemia on internal $\mathrm{Na}^{+}$and $\mathrm{K}^{+}$contents in the SOL muscles after CSD experiments for $3 \mathrm{hr}$. In addition, when the rats were deeply anesthetized with pentobarbital, the muscle Na-pump was also activated.

There were no differences among the recovered $\mathrm{Na}^{+}$and $\mathrm{K}^{+}$contents after peripheral sections, spinal cord transection, brainstem transection, decerebration, and cortical spreading depression. The results suggest that the CNS of hypokalemic rats in some way act to inhibit the active $\mathrm{Na}^{+}-\mathrm{K}^{+}$transport mechanism in SOL muscle in vivo since the length of residual nerve stumps does not account for the recovery of the $\mathrm{Na}^{+}$and $\mathrm{K}^{+}$contents in the denervated SOL muscles. 


\section{Effect of ouabain}

Ouabain, a specific inhibitor of $\mathrm{Na}^{+}-\mathrm{K}^{+}$dependent ATPase, was used in determining whether the $\mathrm{Na}^{+}$excretion and $\mathrm{K}^{+}$uptake in the denervated SOL muscles in vivo of hypokalemic rats result from the activation of the Na-pump. One muscle from each pair of SOL muscles from hypokalemic rats was prepared for $\mathrm{Na}^{+}$and $\mathrm{K}^{+}$analysis as a control immediately after ether anaesthesia. Then, the tibial nerve branch of the companion muscle was sectioned $15 \mathrm{~min}$ after the intravenous injection of ouabain $(0.1$ to $1 \mathrm{mg} / \mathrm{kg}$ body weight). It should be pointed out that these concentrations of ouabain do not cause any changes of $[\mathrm{Na}]_{\mathrm{i}}$ and $[\mathrm{K}]_{\mathrm{i}}$ in the "fresh" SOL muscles of normal rats. One hour following the ouabain treatment, the denervated companion muscle was dissected from the animal for ion analysis. The average amounts of $[\mathrm{Na}]_{\mathrm{i}}$ and $[\mathrm{K}]_{\mathrm{i}}$ in control SOL muscles were $73.0 \pm 3.7$ and $78.2 \pm 3.4 \mathrm{mmol} /$ liter fiber water $(N=10)$, while those in the denervated companion muscles treated with ouabain were $71.8 \pm 3.0$ and $80.5 \pm 3.2 \mathrm{mmol} /$ liter fiber water, respectively. The results show that the $\mathrm{Na}^{+}$extrusion and $\mathrm{K}^{+}$uptake in the denervated SOL muscles were completely abolished by the pre-treatment of ouabain. Therefore, ouabain-sensitive Na-pump must be involved in the denervatoin-induced recovery of the $\mathrm{Na}^{+}$and $\mathrm{K}^{+}$contents of the SOL muscle in vivo of hypokalemic rats, as found previously in the preparation in vivo (AKAIKE, 1974, 1975, 1976).

\section{Effect of TTX}

It becomes important to know whether a dramatic reversal of the effects of hypokalemia on the Na-pump in SOL muscles by sectioning the nerve may result from the deprivation of neural activity or the interruption of axonal flow may be responsible for the internal cation recovery. Therefore, a part of the sciatic nerve on one side of hypokalemic rats was treated with TTX at the concentration of $10^{-5} \mathrm{~g} / \mathrm{ml}$ by means of the slow-release technique (MILLs and BRAY, 1979), since TTX blocks nerve conduction but not axonal flow. After $3 \mathrm{hr}$ both innervated SOL muscles were dissected out and prepared for $\mathrm{Na}^{+}$and $\mathrm{K}^{+}$analyses. There was a considerable recovery of the effects of hypokalemia on $[\mathrm{Na}]_{\mathrm{i}}$ or $[\mathrm{K}]_{\mathrm{i}}$ in the innervated muscles on the TTX-treated side (Table 2). It is evident from the results that some factors associated with peripheral neural activity suppress the Na-pump mechanism in the rat SOL muscles during hypokalemia.

\section{Effects of curare and atropine}

The participation of a neurotransmitter receptor in the suppression of the active $\mathrm{Na}^{+}-\mathrm{K}^{+}$transports in SOL muscles by the CNS was examined. Curare was used to determine whether the neural inhibition on Na-pump in innervated SOL muscles is mediated by ACh. One muscle from each pair of SOL muscles from hypokalemic rats was prepared for $\mathrm{Na}^{+}$and $\mathrm{K}^{+}$analyses as a control. The innervated companion muscle remained in vivo for an additional hour after an intravenous injection of curare $(1.5 \mathrm{mg} / \mathrm{kg}$ body weight), during that time the rats 
Table 2. Effects of TTX, curare, and atropine on the active $\mathrm{Na}^{+}-\mathrm{K}^{+}$ transports in SOL muscles of hypokalemic rats.

\begin{tabular}{|c|c|c|c|}
\hline Preparation & $\begin{array}{l}\text { Muscle } \\
\text { weight } \\
\text { (mg) }\end{array}$ & $\begin{array}{l}{[\mathrm{Na}]_{\mathrm{i}}} \\
(\mathrm{mmol} / \mathrm{li}\end{array}$ & $\begin{array}{c}{[\mathrm{K}]_{1}} \\
\text { er water) }\end{array}$ \\
\hline Control muscles & $85 \pm 3.3(6)$ & $74.1 \pm 1.3$ & $75.0 \pm 1.5$ \\
\hline TTX & $86 \pm 2.6(6)$ & $43.3 \pm 2.1$ & $102.5 \pm 2.8$ \\
\hline Net change & & $(-30.8)^{*}$ & $(+27.5)^{*}$ \\
\hline Control muscles & $96 \pm 2.8(22)$ & $72.5 \pm 3.6$ & $75.8 \pm 3.8$ \\
\hline Curare & $95 \pm 2.4(6)$ & $72.2 \pm 3.1$ & $74.5 \pm 2.3$ \\
\hline Net change & & $(-0.3)$ & $(-1.3)$ \\
\hline Curare + denervation & $94 \pm 3.3(8)$ & $44.4 \pm 2.7$ & $108.5 \pm 2.2$ \\
\hline Net change & & $(-28.1)^{*}$ & $(+32.7)^{*}$ \\
\hline $\begin{array}{l}\text { Curare }+ \text { denervation } \\
\quad+\text { electrical stimuli }\end{array}$ & $98 \pm 3.8(8)$ & $70.1 \pm 3.0$ & $77.1 \pm 3.1$ \\
\hline Net change & & $(-2.4)$ & $(+1.3)$ \\
\hline Control muscles & $97 \pm 3.5(12)$ & $72.0 \pm 2.7$ & $72.7 \pm 2.3$ \\
\hline Atropine & $98 \pm 2.7(6)$ & $73.0 \pm 3.0$ & $74.4 \pm 2.8$ \\
\hline Net change & & $(+1.0)$ & $(+1.6)$ \\
\hline Atropine + denervation & $95 \pm 2.8(6)$ & $42.0 \pm 3.3$ & $105.2 \pm 3.1$ \\
\hline Net change & & $(-30.0)^{*}$ & $(+32.5)^{*}$ \\
\hline
\end{tabular}

Muscles were maintained in vivo for $3 \mathrm{hr}$ after denervation or drug treatment. In curare- and atropine-treated rats, however, the muscles were dissected out after $1 \mathrm{hr}$ of the treatments. TTX, $10^{-5} \mathrm{~g} / \mathrm{ml}$; curare, $1.5 \mathrm{mg} / \mathrm{kg}$ body weight i.v.; atropine-sulfate, $1.5 \mathrm{mg} / \mathrm{kg}$ body weight i.p. Symbols (*) indicate significant difference at $P<0.001$. Numerals inside the parentheses indicate number of muscles measured.

were maintained under artificial respiration. Then, the innervated companion muscle was prepared for the electrolyte analysis. The block of neuromuscular transmission by curare did not elicit the recovery of $\mathrm{Na}^{+}$and $\mathrm{K}^{+}$contents in SOL muscles of hypokalemic rats (Table 2).

In the second experimental series of curare treatment, one muscle from a pair of SOL muscles was prepared for the electrolyte analysis as a control while the contralateral tibial nerve section was carried out after curare injection. Then, the denervated SOL muscle remained in vivo for an additional hour. There was remarkable recovery of $\mathrm{Na}^{+}$and $\mathrm{K}^{+}$contents in denervated SOL muscles of curarized animals (Table 2).

The intraperitoneal injection of atropine $(1.5 \mathrm{mg} / \mathrm{kg}$ body weight) had no effect on $\mathrm{Na}^{+}$and $\mathrm{K}^{+}$contents in SOL muscles, but the successive denervation could activate the active $\mathrm{Na}^{+}-\mathrm{K}^{+}$transport in SOL muscle, as found in the denervated SOL muscles of curarized hypokalemic rats (Table 2). The over-all results suggest that the CNS inhibition on the Na-pump in SOL muscle of hypokalemic rat is probably not mediated by $\mathrm{ACh}$ and also that the effect of denervation on SOL muscles in hypokalemic rats is not due to the immobilization of the muscles. 


\section{Electrical stimulation of distal nerve stump in the presence of curare}

As described above, the blockage of neuromuscular transmission by curare had no effect on the internal cation contents of the innervated SOL muscles of hypokalemic rats. Thus, it becomes a matter of great concern to make sure whether the failure in nerve conduction following denervation causes the facilitation of active $\mathrm{Na}^{+}$and $\mathrm{K}^{+}$transports in SOL muscles.

Hypokalemic rats were anaesthetized with ether and the sciatic nerve of one side was exposed. The nerve was placed on stimulating and recording electrodes and covered with paraffin oil at $37^{\circ} \mathrm{C}$ by an infrared lamp. Thereafter, rats were curarized using curare $(1.5 \mathrm{mg} / \mathrm{kg}$ body weight, i. v. $)$ and maintained by artificial respirator. Then, repetitive stimulation of $30 \mathrm{~V}$ to the distal nerve stump was made as soon as the unilateral SOL muscle has been denervated acutely at about the $0.5 \mathrm{~cm}$ level before the entry of sciatic nerve into spinal cord. Single stimulus was square wave pulse of $0.1 \mathrm{msec}$ duration spaced at $10 \mathrm{cps}$. Compound action potentials elicited by electrical stimuli were monitored by recording electrodes placed about $1 \mathrm{~cm}$ peripherally to stimulating electrodes. After electrical stimulation of the distal nerve stump for $1 \mathrm{hr}$ following nerve section, the denervated SOL muscle was dissected out, prepared for the electrolyte analysis and compared with $\mathrm{Na}^{+}$and $\mathrm{K}^{+}$contents in the innervated control muscle. It is evident in Table 2, in which the recovery of internal cation contents in the denervated SOL muscle was completely ceased by applying electrical stimulation to the distal nerve stump. Thus, it seems clear that the Na-pump in rat SOL muscle during hypokalemia is regulated by neural activity, and that the result complements the interpretation of the TTX data described above.

\section{Effects of $\alpha$ - and $\beta$-adrenoreceptor antagonists}

A series of present experiments suggests that the CNS-induced inhibition on the active $\mathrm{Na}^{+}-\mathrm{K}^{+}$transport in the innervated SOL muscle of hypokalemic rats is mediated by endogenous substance but not by ACh. According to DURY (1951) and LEITCH et al. (1976), catecholamines produce hypokalemia in intact organisms. Therefore, $\alpha$ - and $\beta$-adrenoreceptor antagonists were used to examine whether catecholamines might mediate the CNS-induced suppression on the active $\mathrm{Na}^{+}$$\mathrm{K}^{+}$transports in the innervated SOL muscles during hypokalemia.

One muscle from a pair of SOL muscles of hypokalemic rats was prepared for the electrolyte analysis as a control. The contralateral innervated muscle remained in vivo for $3 \mathrm{hr}$ after intraperitoneal injection of $\alpha$ - or $\beta$-adrenoreceptor antagonists. The results are summarized in Table 3. At the dosage tested, three $\alpha$-adrenoreceptor antagonists such as dibemanine, phentolamine, and phenoxybenzamine reduced the CNS-induced inhibition on the muscle Na-pump in the order of phenoxybenzamine $>$ dibenamine $>$ phentolamine. Prazosin, as the most specific blocker of postsynaptic $\alpha_{1}$-adrenoreceptors (STARKE and DocherTY, 1980), could also inhibit the CNS-induced suppression on the Na-pump. Propranolol, as 
Table 3. Effects of $\alpha$ - and $\beta$-adrenoreceptor antagonists on the active $\mathrm{Na}^{+}-\mathrm{K}^{+}$ transports of SOL muscles of hypokalemic rats for 5 to 9 weeks.

\begin{tabular}{|c|c|c|c|}
\hline Preparation & $\begin{array}{c}\text { Muscle } \\
\text { weight } \\
\text { (mg) }\end{array}$ & \multicolumn{2}{|c|}{ (mmol/liter fiber water) } \\
\hline Control & $71 \pm 3.5(15)$ & $74.2 \pm 2.3$ & $75.0 \pm 2.1$ \\
\hline Phenoxybenzamine & $73 \pm 3.2(15)$ & $53.4 \pm 1.7$ & $96.3 \pm 2.8$ \\
\hline Net change & & $(-20.8)^{*}$ & $(-21.3)^{*}$ \\
\hline Control & $91 \pm 3.5(15)$ & $72.8 \pm 2.8$ & $74.0 \pm 2.0$ \\
\hline Phentolamine & $89 \pm 4.5(15)$ & $64.8 \pm 2.3$ & $80.4 \pm 2.5$ \\
\hline Net change & & $(-8.0)^{*}$ & $(+6.4)^{*}$ \\
\hline Control & $88 \pm 5.4(15)$ & $73.6 \pm 2.0$ & $73.5 \pm 3.1$ \\
\hline Dibenamine & $91 \pm 3.9(15)$ & $58.6 \pm 2.3$ & $89.9 \pm 3.3$ \\
\hline Net change & & $(-15.0)^{*}$ & $(+16.4)^{*}$ \\
\hline Control & $85 \pm 2.8(8)$ & $75.3 \pm 2.3$ & $76.8 \pm 2.8$ \\
\hline Prazosin & $83 \pm 3.3(8)$ & $62.3 \pm 2.2$ & $91.0 \pm 2.6$ \\
\hline Net change & & $(-13.0)^{*}$ & $(+14.2)^{*}$ \\
\hline Control & $79 \pm 2.8(8)$ & $72.6 \pm 3.2$ & $76.4 \pm 3.7$ \\
\hline Propranolol & $80 \pm 2.7(8)$ & $71.7 \pm 3.1$ & $78.3 \pm 3.3$ \\
\hline Net change & & $(-1.5)$ & $(+1.9)$ \\
\hline Control & $72 \pm 3.5(6)$ & $74.1 \pm 2.6$ & $75.6 \pm 2.5$ \\
\hline Propranolol + denervation & $74 \pm 5.1(6)$ & $43.5 \pm 2.3$ & $107.0 \pm 3.0$ \\
\hline Net change & & $(-30.6)^{*}$ & $(+31.4)^{*}$ \\
\hline
\end{tabular}

Muscles were maintained in vivo for $3 \mathrm{hr}$ after the drug injection. Phenoxybenzamine, dibenamine, and prazosin, $1 \mathrm{mg} / \mathrm{kg}$ body weight i.p.; phentolamine, $1 \mathrm{mg} / \mathrm{kg}$ body weight i.p. for each hour; propranolol, $0.5-2.0 \mathrm{mg} / \mathrm{kg}$ weight i.p. Symbols (*) indicate significant difference at $P<0.001$. The number of muscles is shown in parentheses.

$\beta_{1}$-selective adrenoreceptor antagonist, did not produce any detectable changes in the internal cation contents. Also, the denervation effect on the muscle $\mathrm{Na}^{+}$and $\mathrm{K}^{+}$contents was not affected by the pretreatment of propranolol, indicating that the facilitation of active $\mathrm{Na}^{+}$and $\mathrm{K}^{+}$transports by denervation is not due to $\beta$ adrenoreceptor mediated stimulation of the Na-pump (Table 3). These results suggest that $\alpha_{1}$-adrenoreceptor on the SOL muscle membrane of hypokalemic rats plays an important role in mediating CNS-induced inhibition on the active Na-pump mechanism and that the endogenous transmitter may be noradrenaline.

\section{DISCUSSION}

In the present experiments, sectioning the tibial nerve branch, sciatic nerve, spinal cord, brainstem, the decerebration or CSD, and blocking sciatic nerve impulses by TTX results in a rapid restoration of $[\mathrm{Na}]_{i}$ and $[\mathrm{K}]_{\mathrm{i}}$ levels in the denervated SOL muscles of hypokalemic rats to levels nearer those found in "fresh" SOL muscles of normal rats. The denervation-induced activation of $\mathrm{Na}^{+}-\mathrm{K}^{+}$transports in the denervated SOL muscles of hypokalemic rats was ouabain-sensitive and 
appeared even in the presence of curare and atropine. The activation of Na-pump in the denervated SOL muscles of curarized hypokalemic rats was blocked by applying electrical stimuli at high voltages to the distal cut nerve. The results suggest that the changes in muscle activity or tone in the presence of curare are not involved in the activation of the Na-pump in the denervated SOL muscles. Furthermore, the Na-pump in the innervated SOL muscles was activated by phentolamine, phenoxybenzamine, and dibenamine as $\alpha$-adrenoreceptor antagonists, especially by prazosin as a specific antagonist of postsynaptic $\alpha_{1}$-adrenergic receptors but not by propranolol as a $\beta$-adrenoreceptor antagonist. The results mentioned above suggest that CNS inhibits the active $\mathrm{Na}^{+}-\mathrm{K}^{+}$transports in SOL muscle during hypokalemia and that the CNS-induced inhibition on the Na-pump is probably mediated by the endogenous transmitter, noradrenaline, released from the peripheral nerve ending by neural activity. The catecholamine seems to act directly on $\alpha_{1}$-adrenoreceptors in SOL muscle membrane.

Recent anatomical experiments have revealed that a noradrenergic autonomic innervation is distributed to not only blood vessels but also to both intraand extrafusal muscle fibers of rats and cats (SANTINI and IBATA, 1971; BARKER and SAITo, 1981). Catecholamines activate an active $\mathrm{Na}^{+}-\mathrm{K}^{+}$transport in SOL muscles and augment the resting membrane potential of the muscles of normal rat and guinea-pig by activating $\beta$-adrenoreceptors on the cellmemb rane (DOCKRY et al., 1966; TAShiro, 1973; Flatman and Clausen, 1978; Clausen and Flatman, 1980). Catecholamines also have a stimulating effect on the Na-pump of the isolated cardiac cells (WADDELl, 1961; GlitsCH et al., 1965; STAFFORD, 1962; VASSORT et al., 1969). In dog cardiac Purkinje fiber perfused in vitro, small concentrations of noradrenaline reduce $\mathrm{K}^{+}$uptake by depressing the function of $\mathrm{Na}$ pump while larger concentrations increase $\mathrm{K}^{+}$uptake by stimulating Na-pump. The inhibition and facilitation of $\mathrm{K}^{+}$influx by different concentrations of noradrenaline is $\alpha$ - and $\beta$-functions, respectively (Posner and VAssalle, 1971). Thus, both adrenergic $\alpha$ - and $\beta$-receptors may exist on the mammalian skeletal muscle membrane and that the activation of Na-pump in the presence of catecholamine may be due to the activation of $\beta$-adrenoreceptors or the inhibition of $\alpha$-adrenoreceptors.

Potassium-deficient diets cause plasma hypokalemia and decrease cellular $\mathrm{K}^{+}$contents in skeletal, heart, and smooth muscles, while $\mathrm{K}^{+}$contents of the brain such as cerebrum, cerebellum, medulla oblongata and spinal cord, cerebrospinal fluid, and liver are unchanged (JoHAnson et al., 1974; AKaIKe, 1981). The present in vivo results show that CNS can inhibit the activity of the Na-pump in a typical "tonic" muscle, SOL, during hypokalemia by the activation of $\alpha_{1}$-adrenoreceptors on the cell membrane. It is possible that CNS acts to preserve the $\mathrm{Na}^{+}$and $\mathrm{K}^{+}$ contents in certain vital organs by regulation of the distribution of these ions in the body. At least in the initial stages of hypokalemia, less vital tissue as skeletal muscle may serve as a source of $\mathrm{K}^{+}$. A slow net release of $\mathrm{K}^{+}$from these less 
vital organs may have a physiological means as "buffer" between the animal's intake of $\mathrm{K}^{+}$and its plasma $\mathrm{K}^{+}$concentration. The freed $\mathrm{K}^{+}$could then be taken up by certain more vital organs such as brain and liver to maintain homeostasis and/or function. It is not clear, however, whether this mechanism is active only during hypokalemia or is tonically active.

The authors would like to thank Professors Y. Oomura, T. Hori, and K. Nishi for their valuable suggestions in the preparation of this manuscript. The present study was partly supported by the Grant from the Muscular Dystrophy Association, U.S.A. to N. Akaike.

\section{REFERENCES}

AKaIKe, N. (1974) Operation of an electrogenic Na-pump in mammalian red muscle fibre. Life Sci., 14: 141-147.

AKaIKE, N. (1975) Contribution of an electrogenic sodium pump to membrane potential in mammalian skeletal muscle fibres. J. Physiol. (Lond.), 245: 499-520.

AKAIKE, N. (1976) Intracellular ion concentration and electrical activity in potassium-depleted mammalian soleus muscle fibers. Pfügers Arch., 362: 15-20.

Akaike, N. (1979) CNS effects on muscle Na/K levels in hypokalemia. Brain Res., 178: 175178.

AkaIKE, N. (1981) Sodium pump in skeletal muscle: Central nervous system-induced suppression by $\alpha$-adrenoreceptors. Science, 213: 1252-1254.

Akaike, N., Hirata, A., Kiyohara, T., and Oyama, Y. (1983) Neural regulation on the active Na-K transport in hypokalemic rat skeletal muscles. J. Physiol. (Lond.), 341 : in press.

BARKer, D. B. and SaIto, M. (1981) Autonomic innervation of receptors and muscle fibres in cat skeletal muscle. Proc. R. Soc. Lond. (Biol.), 212: 317-332.

Bradbury, M. W. B. and Kleeman, C. R. (1967) Stability of the potassium content of cerebrospinal fluid and brain. Am. J. Physiol., 213: 519-528.

BUREŠ, J. and BUREŠOvÁ, O. (1972) Inducing cortical spreading depression. In: Methods in Psychology, ed. by MYers, R. D. Academic Press, Inc., London, Vol. 2, pp. 319-343.

Bureš, J., Burešoví, O., and KŘrvánek, J. (1974) The Mechanism and Applications of Lẽao's Spreading Depression of Electroencephalographic Activity, Academia, Prague.

Clausen, T. and Flatman, J. A. (1980) $\beta_{2}$-Adrenoreceptors mediate the stimulating effect of adrenaline on active electrogenic Na-K-transport in rat soleus muscle. Br. J. Pharmacol., 68: 749-755.

DESMEDT, J. E. (1953) Electrical activity and intracellular sodium concentration in frog muscle. J. Physiol. (Lond.), 121: 191-205.

Dockry, M., Kernan, R. P., and TANGney, A. (1966) Active transport of sodium and potassium in mammalian skeletal muscle and its modification by nerve and by cholinergic and adrenergic agents. J. Physiol. (Lond.), 186: 187-200.

Dury, A. (1951) The effect of epinephrine and insulin on the plasma potassium level. Endocrinology, 49: 663-670.

Flatman, J. A. and Clausen, T. (1978) $\beta_{2}$-Adrenoreceptors mediate the stimulating effect of adrenaline on active electrogenic $\mathrm{Na}^{+}-\mathrm{K}^{+}$-transport in rat soleus muscle. Acta Physiol. Scand., 102: 61-62.

Glitsch, H. G., Hass, H. G., and Trautwein, W. (1965) The effect of adrenaline on the K and $\mathrm{Na}$ fluxes in the frog's atrium. Naunyn Schmiedebergs Arch. Pharmakol., 250: 59-71.

Guth, L. (1968) "Trophic” influence of nerve on muscle. Physiol. Rev., 48: 645-687.

Johanson, C. E., ReED, D. J., and Woodbury, D. M. (1974) Active transport of sodium and

Vol. 33, No. 3, 1983 
potassium by the choroid plexus of the rat. J. Physiol. (Lond.), 241: 359-372.

KIYOHARA, T. (1968) Cation concentration change following denervation of rat skeletal muscle. Kumamoto Med. J., 21: 179-187.

KöNIG, J. F. R. and KLIPPEL, R. A. (1963) The Rat Brain: A Stereotaxic Atlas of the Forebrain and Lower Parts of the Brain Stem, Williams and Wilkins, Baltimore.

LẼAO, A. A. P. (1947) Further observations on spreading depression of activity in cerebral cortex. J. Neurophysiol., 10: 409-414.

Leitch, A. G., Clancy, L. J., Costello, J. F., and Flenley, D. C. (1976) Effect of intravenous infusion of salbutamol on ventilatory response to carbon dioxide and hypoxia and on heart rate and plasma potassium in normal men. Br. Med. J., 1: 365-367.

Mills, R. G. and BRAY, J. J. (1979) A slow-release technique for inducing prolonged paralysis by tetrodotoxin. Pflügers Arch., 383: 67-70.

Nattie, E. E. (1977) Brain tissue potassium in normal and potassium depleted rats. Life Sci., 21: 1851-1856.

NørgaArd, A., Kueldsen, K., and Clausen, T. (1981) Potassium depletion decreases the number of ${ }^{3} \mathrm{H}$-ouabain binding sites and the active sodium-potassium-transport in skeletal muscle. Nature, 293: 739-741.

PoSNer, P. and VASSAlle, M. (1971) The inhibitory action of norepinephrine on potassium uptake in cardiac Purkinje fibres. T.-I.-T. J. Life Sci., 1: 67-78.

RedFern, P. and THESLEFF, S. (1971) Action potential generation in deneravated rat skeletal muscle. II. The action of tetrodotoxin. Acta Physiol. Scand., 87: 70-78.

Santini, M. and Ibata, Y. (1971) The fine structure of thin unmyelinated axons within muscle spindles. Brain Res., 33: 289-302.

StAFFORD, A. (1962) Adrenaline, antiadrenaline drugs and potassium movements in rabbit auricles. Br. J. Pharmacol., 19: 274-285.

Starke, K. and Docherty, J. R. (1980) Recent developments in $\alpha$-adrenoreceptor research. J. Cardiovasc. Pharmacol., 2: 269-286.

TASHIRO, N. (1973) Effects of isoprenaline on contraction of directly stimulated fast and slow skeletal muscles of the guinea-pig. Br. J. Pharmacol., 48: 121-131.

TheslefF, S. and Ward, M. R. (1975) Studies on the mechanism of fibrillation potentials in denervated muscle. J. Physiol. (Lond.), 244: 313-323.

Vassort, G., Rougier, O., Garnier, P., Sauviat, A., Coraboeuf, E., and Gargouil, Y. M. (1969) Effect of adrenaline on membrane inward currents during the cardiac action potential. Pflügers Arch., 309: 70-81.

WADDELL, A. M. (1961) Adrenaline, noradrenaline and potassium fluxes in rabbit auricles. $J$. Physiol. (Lond.), 155: 209-220. 